\title{
Kebiasaan makan ikan gelodok (Famili: Gobiidae) lokal Jawa Timur
}

\author{
Food habits of local gelodok fish (Family: Gobiidae) in East Java
}

\author{
Anisya Eka Juniar, Syefrina Rosyada, Ahnan Mahfudz Nur S, Dwi Anggorowati Rahayu* \\ Jurusan Biologi, Fakultas MIPA Universitas Negeri Surabaya \\ Jalan Ketintang, Ketintang, Gayungan, Kota Surabaya, Jawa Timur 60231 \\ *Email: dwirahayu@unesa.ac.id
}

Diterima 9 September 2019 Disetujui 6 Desember 2019

\section{INTISARI}

Ikan gelodok termasuk dalam Famili Gobiidae Subfamili Oxudercinae terbagi mencapai 10 genus dan 36 spesies dan sebagian besar terdistribusi di wilayah Indo-Pasific serta Oceania. Kebiasaan makanan ikan gelodok meliputi jenis makanan, frekuensi kejadian dan nilai bagian terbesar dari komposisi makanannya. Metode yang dilakukan yaitu survei melalui penyisiran di lokasi-lokasi pengambilan sampel ikan gelodok yaitu di empat lokasi yang berbeda. Hasil penelitian diperoleh dua kelompok makanan besar ikan gelodok yaitu Fitoplankton terdiri atas Nitzschia sp., Pleurosigma sp., Coscinodiscus sp., Biddulphia sp., Chaetocheros sp., Thalassiothrix sp. dan Embrio ikan. Ikan gelodok yang ditemukan dari keempat lokasi adalah herbivora. Presentase nilai satu jenis makanan atau nilai $\mathrm{N}_{\mathrm{i}}$ diperoleh jenis makanan dengan ukuran diameter yang besar pada organ pencernaan ikan gelodok ialah dari spesies jenis makanan Coscinodiscus sp., Biddulphia sp., Pleurosigma sp.

Kata kunci: ikan gelodok, kebiasaan makan, jenis makanan

\begin{abstract}
Mudskippers included in the Gobiidae Subfamily Family Oxudercinae, divided into 10 genera and 36 species, most of which are distributed in the Indo-Pacific and Oceania regions. Mudskipper food habits include the type of food, the frequency of occurrence, and the value of the largest part of its food composition. The method used is a survey through the combining locations of fish sampling in four different locations. The results obtained by two large food groups are phytoplankton consisting of Nitzschia sp., Pleurosigma sp., Coscinodiscus sp., Biddulphia sp., Chaetocheros sp., Thalassiothrix sp. and fish embryos. Mudskipper fish found from all four locations are herbivores. Percentage of the value of one type of food or the value of $\mathrm{Ni}$ obtained by food species with a large diameter size in the digestive organs of fish geese is from food species Coscinodiscus sp., Biddulphia sp., Pleurosigma sp.
\end{abstract}

Keywords: mudskipper, food habits, type of foods

\section{PENDAHULUAN}

Indonesia merupakan salah satu negara yang memiliki kepulauan sangat luas dan dikelilingi oleh lautan terbagi atas zona maritim yang luas, yaitu mencapai 5,8 juta $\mathrm{km}^{2}$ terdiri atas beberapa bagian perairan laut meliputi perairan kepulauan sebesar 2,3 juta $\mathrm{km}^{2}$, laut territorial sebesar 0,8 juta $\mathrm{km}^{2}$ dan perairan Zona Ekonomi Eksklusif sebesar 2,7 juta $\mathrm{km}^{2}$ (Departemen Kelautan dan Perikanan, 2009) Berdasarkan astronomis 
wilayah Jawa Timur memiliki letak pada 111,1'114,4' Bujur Timur dan 7, 12'-8, 48' Lintang Selatan. Luas Provinsi Jawa Timur sebesar $46.428,57 \mathrm{~km}^{2}$ yang terbagi atas wilayah darat dan laut (Peraturan Daerah Provinsi Jawa Timur, 2012). Wilayah laut perairan Jawa Timur memiliki keanekaragaman ikan air laut maupun air tawar salah satunya ialah ikan dari famili Gobidae yaitu ikan gelodok.

Ikan gelodok merupakan salah satu ikan air tawar termasuk ke dalam anggota Famili Gobiidae dan Subfamili Oxudercinae. Ikan Gelodok terbagi menjadi 10 genus dengan 36 spesies. Sebagian besar ikan gelodok di perairan Indonesia terdistribusi di beberapa wilayah IndoPasific serta Oceania (Takita et al., 1999). Menurut Gordon (1998) ikan gelodok juga dikenal atau dijuluki sebagai Amphibious Fish, berdasarkan sejarah hidupnya ikan gelodok mampu bertahan hidup di dalam maupun di bagian atas permukaan air. Ikan gelodok memiliki ragam jenis dan spesies dilihat dari ciri morfologi. Hasil penelitian Wilis (2012) yang dilakukan di daerah pertambakan Kabupaten Tuban ditemukan keberadaan ikan gelodok dengan jenis Baleophthalmus boddarti, sedangkan hasil penelitian Angggara (2013) yang dilakukan di Muara Sungai Porong Kabupaten Sidoarjo ditemukan jenis ikan gelodok sebanyak tiga spesies meliputi Boleophthalmus pectinirostris, Boleophthalmus boddarti serta Periophthalmodon schlosseri. Juniar dkk. (2019) menemukan empat spesies ikan Mudskipper dari ketiga lokasi penelitian yaitu Boleophthalmus boddarti, Periopthalmus novemradiatus, Periopthalmus mallacensis, dan Periophthalmodon septemradiatus.

Makanan merupakan salah satu faktor penting bagi kehidupan ikan karena dapat membantu menentukan luas wilayah persebaran keberadaan ikan dan juga dapat digunakan sebagai monitoring jumlah populasi ikan di suatu wilayah. Persson \& De Ross (2006) menyatakan bahwa makanan berperan sebagai faktor pengontrol dan pembatas terhadap pertumbuhan setiap individu dan populasi ikan yang berada di perairan. Tolok ukur kebiasaan makan ikan (food habits) meliputi paramater kuantitas dan kualitas jenis maupun jumlah makanan yang dikonsumsi oleh ikan (Effendi, 1979).

Hasil penelitian Wilis (2012) terkait kebiasaan makanan ikan gelodok di Kabupaten Tuban diperoleh tiga kelompok besar makanan utama yaitu Skeletonema sp., Nitzchia sp., dan Pleurosigma sp. Selanjutnya hasil penelitian Manuel (2011) diperoleh jenis makanan meliputi crustacean, insect, polychaeta dan Alga. Penelitian kebiasaan makan ikan Gelodok di Jawa Timur masih kurang merata. Maka dari itu diperlukan perkembangan informasi lebih lanjut mengenai kebiasaan makan ikan gelodok lokal Jawa Timur.

\section{MATERI DAN METODE}

\section{Tempat dan Waktu Penelitian}

Penelitian ini telah dilakukan selama 5 bulan, dimulai dari bulan Februari hingga Juni 2019. Pengambilan sampel hidup ikan gelodok diperoleh dari 4 (empat) lokasi yang berbeda meliputi Pantai Kenjeran, Tambak Mangrove Wonorejo, Tambak Sedati, Mangrove Mengare (Gambar 1).

\section{Bahan dan Alat}

Alat-alat yang digunakan dalam penelitian ini ialah jaring, pancing, toples plastik., $\mathrm{pH}$ indikator, refraktometer, thermometer dan kamera digital. Bahan meliputi sampel ikan Gelodok, alkohol $70 \%$ dan formalin $4 \%$.

\section{Pengambilan Sampel}

Penelitian ini telah dilakukan selama 5 bulan, dimulai dari bulan Februari hingga Juni 2019. Pengambilan sampel hidup ikan gelodok diperoleh dari 4 (empat) lokasi yang berbeda meliputi Pantai Kenjeran, Tambak Mangrove Wonorejo, Tambak Sedati, Mangrove Mengare (Gambar 1). 


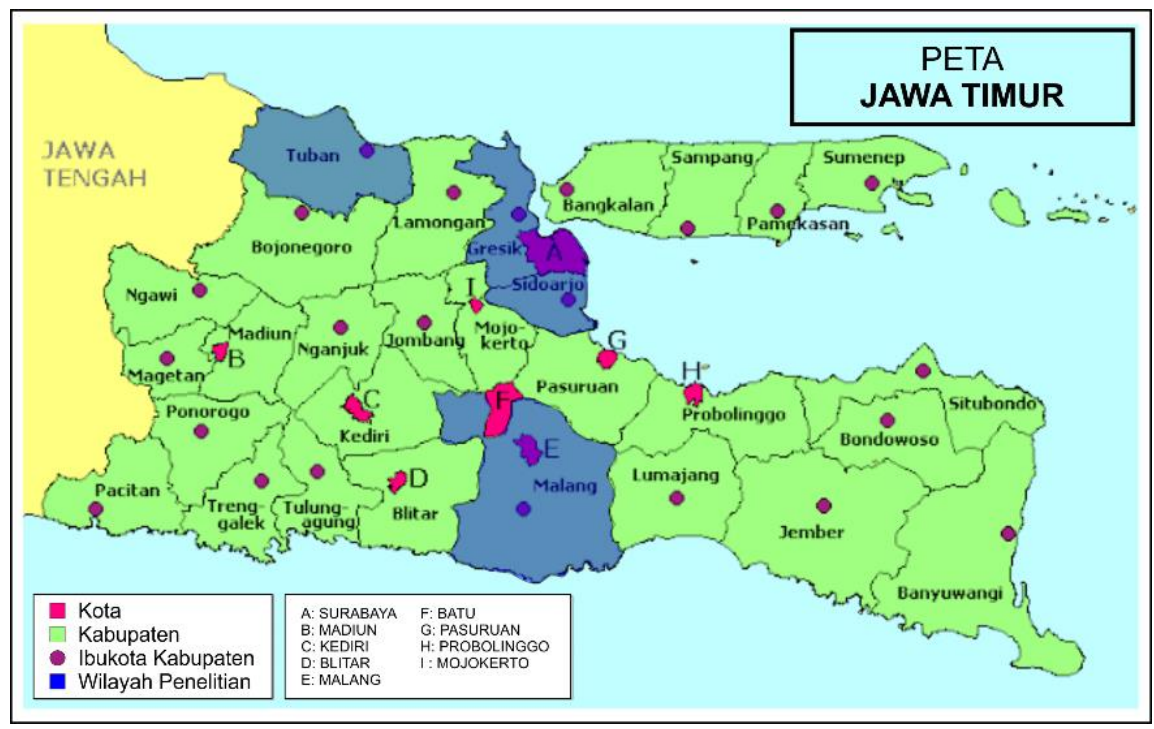

Gambar 1. Peta lokasi pengambilan sampel ikan gelodok Jawa Timur

\section{Pengamatan Kebiasaan Makanan}

Sampel ikan yang diperoleh dibersihkan, lalu diambil gambar morfologi ikan sebelum dilakukan pembedahan organ pencernaan ikan gelodok. Pembedahan menggunakan alat bedah yang telah disterilisasi dengan Alkohol 70\%. Organ pencernaan meliputi lambung dan usus diawetkan dengan formalin $4 \%$ dan dimasukkan ke dalam botol vial. Pengamatan terhadap organ pencernaan ikan gelodok menggunakan mikroskop cahaya sehingga diperoleh gambar penampakan jasad makanan ikan gelodok, kemudian diambil gambar menggunakan kamera dan dilakukan identifikasi jenis makanan.

\section{Analisis Data}

Jenis makanan dalam organ pencernaan ikan dilakukan perhitungan nilai frekuensi kejadian jasad makanan. Frekuensi kejadian jasad makanan dilakukan menggunakan rumus sebagai berikut:

$$
\mathrm{F}_{\mathrm{i}}=\underline{\mathrm{Lt}}_{\mathrm{Lt}}^{\mathrm{L}} 100 \%
$$

$\mathrm{F}_{\mathrm{i}}=$ Frekuensi kejadian jasad makanan yang sejenis

$\mathrm{L}_{\mathrm{i}}=$ Jumlah total organ pencernaan ikan yang terdapat jasad makanan sejenis

$\mathrm{L}_{\mathrm{t}}=$ Jumlah total organ pencernaan yang terdapat semua jenis jasad makanan
Nilai Indeks Bagian Terbesar (Index of Preponderance) dari ikan gelodok dapat dilakukan melalui perhitungan menggunakan rumus (Modifikasi rumus dari Natarajan dan Jingran, 1961) dalam Effendi (1979).

$$
\mathrm{I}_{\mathrm{i}}=\frac{\mathrm{N}_{\mathrm{i}} \times \mathrm{F}_{\mathrm{i}}}{\sum\left(\mathrm{N}_{\mathrm{i}} \times \mathrm{F}_{\mathrm{i}}\right)} \times 100 \%
$$

$\mathrm{Ii}=$ Indeks Bagian Terbesar

$\mathrm{Ni}=$ Persentase nilai satu jenis jasad makanan

$\mathrm{Fi}=$ Persentase kejadian satu jenis jasad makanan

$\mathrm{N}_{\mathrm{i}} \times \mathrm{F}_{\mathrm{i}}=\sum \mathrm{Ni}$ x Fi dari semua jenis jasad makanan

\section{HASIL}

\section{Makanan dan Kebiasaan Makan}

Berdasarkan analisis terhadap organ pencernaan dari ikan gelodok yang ditemukan dari keempat lokasi sebagai berikut Boleophthalmus boddarti, $P$. novemradiatus, $P$. mallacensis, $P$. septemradiatus dan $P$. novaeguineaensis diperoleh dua kelompok makanan besar yaitu Fitoplankton terdiri atas Nitzschia sp., Pleurosigma sp., Coscinodiscus sp., Biddulphia sp., Chaetocheros sp., Thalassiothrix sp. dan embrio ikan. Keberadaan komposisi jenis makanan pada organ pencernaan ikan gelodok diperoleh melalui Indeks Bagian Terbesar (Tabel 1). Sedangkan pada presentase nilai satu jenis makanan atau nilai $\mathrm{N}_{\mathrm{i}}$ diperoleh jenis makanan 
dengan ukuran diameter yang besar pada organ pencernaan ikan gelodok yaitu spesies jenis Coscinodiscus sp., Biddulphia sp., Pleurosigma sp. (Gambar 2).

\section{Pengukuran Habitat Ikan Gelodok berdasarkan Ekologi}

Tabel 1. Perhitungan Nilai Indeks Terbesar

\begin{tabular}{lccc}
\hline \multicolumn{1}{c}{ Nama Organisme } & $\mathbf{F}_{\mathbf{i}}(\boldsymbol{\%})$ & $\mathbf{N}_{\mathbf{i}}(\boldsymbol{\%})$ & $\mathbf{I}_{\mathbf{i}}(\boldsymbol{\%})$ \\
\hline Nitzschia sp. & 31.8 & 4.5 & 8.04 \\
Pleurosigma sp. & 31.8 & 6.0 & 10.7 \\
Coscinodiscus sp. & 24.3 & 11.9 & 16.2 \\
Biddulphia sp. & 28 & 10.3 & 16.2 \\
Chaetocheros sp. & 29 & 5 & 8.1 \\
Thalassiothrix sp. & 20 & 29 & 32.6 \\
Embrio Ikan & 29.1 & 4.9 & 8.01 \\
\hline
\end{tabular}

Berdasarkan hasil analisis pengukuran ekologi habitat ikan gelodok dari keempat stasiun diperoleh nilai $\mathrm{pH}$ air mencapai 6.5 hingga 7 dengan suhu air mencapai $29^{\circ} \mathrm{C}$ hingga $33^{\circ} \mathrm{C}$ serta nilai salinitas perairan habitat ikan gelodok mencapai 2.1\%o hingga 3.2\%o (Tabel 2).

Tabel 2. Hasil ekologi habitat ikan gelodok

\begin{tabular}{lcccc}
\hline \multirow{2}{*}{ Parameter } & \multicolumn{4}{c}{ Stasiun Pengamatan } \\
\cline { 2 - 5 } & I & II & III & IV \\
\hline pH air & 7 & 6.5 & 6.5 & 6.7 \\
Suhu air $\left({ }^{\circ} \mathrm{C}\right)$ & 33 & 26 & 26 & 29 \\
Salinitas $(\%$ ) & 3 & 2 & 3.2 & 2.1 \\
\hline
\end{tabular}

Keterangan:

Stasiun I: Pantai Kenjeran

Stasiun II: Tambak Mangrove Wonorejo

Stasiun III: Tambak Sedati Sidoarjo

Stasiun IV: Mangrove Mengare

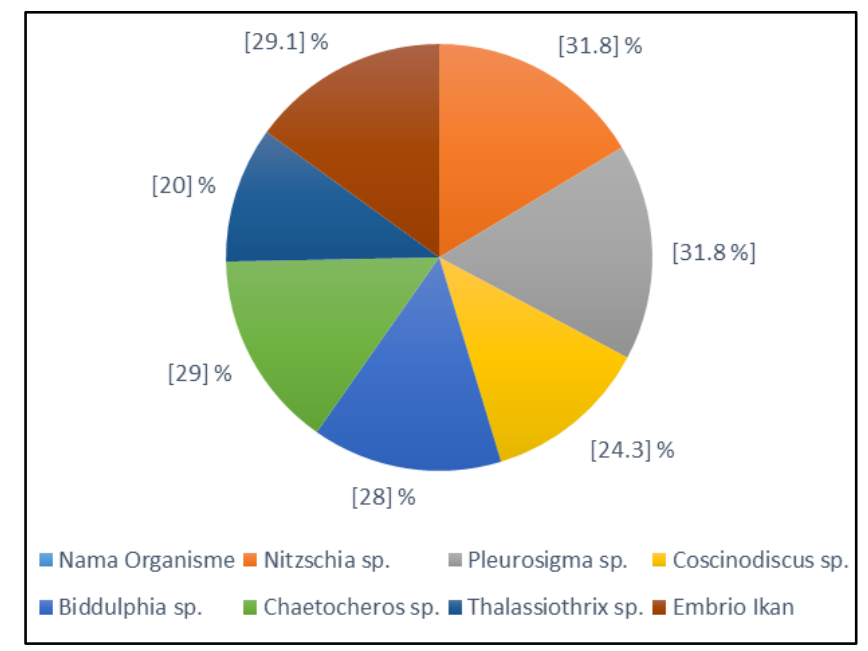

Gambar 2. Nilai Indeks Terbesar makanan ikan gelodok

\section{PEMBAHASAN}

Berdasarkan hasil yang diperoleh dari perhitungan Nilai Indeks Terbesar bahwa pada presentase kejadiaan satu jenis makanan atau nilai dari $F_{i}$ dapat dijelaskan bahwa makanan yang terlihat dari organ pencernaan ikan gelodok didominasi oleh marga diatome. Hal ini sesuai dengan pernyataan Wilis (2012) bahwa ikan gelodok yang ditemukan dari keempat lokasi adalah herbivora. Selain itu berdasarkan presentase nilai satu jenis makanan atau nilai $\mathrm{N}_{\mathrm{i}}$ diperoleh jenis makanan dengan ukuran diameter yang besar pada organ pencernaan ikan gelodok yaitu spesies Coscinodiscus sp., Biddulphia sp., Pleurosigma sp. Hasil penelitian (Yanti, 2000) yang dilakukan di Perairan Ujung Pangkah, Jawa Timur menunjukkan terdapat komponen penyusun jasad makanan dari ikan gelodok yakni termasuk dalam kelompok plankton meliputi fitoplankton dan zooplankton. Berdasarkan hasil 
pengukuran data ekologi dari keempat lokasi pengambilan sampel makanan ikan gelodok diperoleh hasil yang berbeda pada setiap stasiun. Menurut Lukistyowati (1990) menunjukkan peran faktor lingkungan juga dapat memberikan pengaruh terhadap jenis kebiasaan makanan ikan yang ditinjau dari parameter suhu, jenis dan jumlah makanan dan nilai kualitas air habitat ikan. Selain faktor lingkungan, faktor umur dari ikan akan memberikan pengaruh terhadap jenis makanan yang dikonsumsi oleh ikan. Hal tersebut juga didukung oleh perolehan hasil data ekologi dari keempat lokasi ditemukkannya ikan gelodok.

Menurut Romimohtarto (1991) menyatakan $\mathrm{pH}$ perairan dengan nilai sebesar 6 hingga 9 termasuk dalam kisaran normal yang dapat ditolerir bagi kehidupan organisme perairan laut. Hal ini dapat diasumsikan bahwa parameter nilai ekologi dari perairan keempat stasiun memiliki kisaran tolerir pH air kehidupan ikan gelodok, sehingga ikan gelodok dapat tumbuh dan berkembang. Karakteristik khusus suatu substrat dengan dalam bentuk lumpur merupakan habitat berbagai nekton. Hal ini menandakan bahwa daerah tersebut memiliki kekayaan sumber pakan sehingga diperoleh jenis kebiasaan makan ikan yang beragam (Gunarto, 2004).

\section{SIMPULAN}

Kebiasaan makan ikan gelodok diperoleh dua kelompok makanan besar, yaitu fitoplankton terdiri dari Nitzschia sp., Pleurosigma sp., Coscinodiscus sp., Biddulphia sp., Chaetocheros sp., Thalassiothrix sp. dan embrio ikan.

\section{UCAPAN TERIMAKASIH}

Penulis mengucapkan terima kasih kepada Kemristekdikti atas kesempatan yang telah diberikan.

\section{KEPUSTAKAAN}

Anggara. 2013. Studi Populasi Ikan Gelodok (Oxudercinae) Di Muara Sungai Porong, Desa Kedungpandan, Kecamatan Jabon
Kabupaten Sidoarjo. Thesis Sarjana. Universitas Brawijaya.

Departemen Kelautan dan Perikanan. 2009. Peraturan Menteri Kelautan dan Perikanan Nomor PER.03/MEN/2009 tentang Penangkapan Ikan dan atau Pengangkutan Ikan di Laut Lepas. Jakarta: DKP.

Effendie MI. 1979. Metode Biologi Perikanan. Yayasan Dewi Sri: Bogor.

Gordon MS. 1998. African Amphibious Fishes and The Invansion of The Land by The Tetrapods. South African Journal of Zoology 33:115-118.

Gunarto. 2004. Konservasi Mangrove Sebagai Pendukung Sumber Hayati Perikanan Pantai. Jurnal Litbang Pertanian 23(1): 1521.

Juniar AE, Rosyada S, Sholihin AMN, Rahayu DA. 2019. Identifikasi Jenis Ikan Mudskipper di Pantai Surabaya dan Sidoarjo. Jurnal Biotropika 7(3).

Lukistyowati I. 1990. Pengaruh Pemberian Berbagai Dosis Gonadotropin Releasing Hormon (GnRH) terhadap Kematangan Gonad dan Ovulasi Ikan Lele Dumbo. Thesis Pasca Sarjana. Institut Pertanian Bogor. 70 hlm.

Manuel F. 2011. Food and Feeding Ecology of The Mudskipper Periopthalmus koelreuteri (PALLAS) Gobiidae at Rumuolumeni Creek, Niger Delta, Nigeria. Agric Biol J North America 2(6): 897-901.

Pemerintah Provinsi Jawa Timur. 2012. Perda Provinsi Jawa Timur No.5 Tahun 2012 Tentang Rencana Tata Ruanh Wilayah Provinsi Tahun 2011-2031.

Persson L, De Roos AM. (2006). Food-dependent individual growth and population dynamics in fishes. Journal of Fish Biology 69: 1-20.

Romimohtarto K, Sumiyati S. 1998. Kondisi Lingkungan Pesisir dan Laut di Indonesia. Lembaga Oseanologi Nasional Lembaga Ilmu Pengetahuan Indonesia: Jakarta.

Takita T, Agusnimar, Ali AB. 1999. Distribution and habitat requirements of oxudercine 
gobies (Gobiidae: Oxudercinenae) along the Strait of Malaca. Ichthyology Research 46(2): 131.

Wilis S. 2012. Analisa Kebiasaan Makanan Ikan Gelodok (Mudskipper) Jenis Baleophthalmus Boddarti Di Daerah Pertambakan Desa Cepokorejo Kecamatan Palang Kabupaten Tuban. AQUASAINS
Jurnal Ilmu Perikanan dan Sumberdaya Perairan, Fakultas Perikanan dan Kelautan UNIROW Tuban.

Yanti A. 2000. Kebiasaan Makan Ikan Blodok (Boleoptalmus boddarti) di Perairan Ujung Pangkah Jawa Timur. Skripsi. Fakultas Perikanan dan Ilmu Kelautan. Institut Pertanian Bogor: Bogor. 47 hlm. 